\title{
Rethinking Invention: Cognition and the Economics of Technological Creativity
}

\author{
Dr Gary B. Magee \\ Department of Economics \\ The University of Melbourne \\ Parkville VIC 3010, Australia \\ Email:g.magee@unimelb.edu.au
}

Telephone: +6138344 9717; Fax: +61383446899

Economists have typically not devoted much attention to the act of invention. This paper attempts to redress this situation by exploring a form of cognition, analogical transfer, which is thought by some researchers to lie at the heart of successful creativity. An analogical transfer is said to have occurred when information and experiences from one known situation is retrieved and utilized in the search for the solution to an entirely different situation. This paper shows how such analogical thought can give rise to a theoretical framework, in which disparate factors pertaining to technological creativity can be pieced together to yield an explanation of the level of inventive output experienced.

Key words: invention, technological change, technological creativity, problem solving, learning.

J.E.L. Classification(s): O31, D83 


\section{INTRODUCTION}

While most economists accept - even if merely for didactic purposes - Schumpeter's depiction of technological change as a linear process of invention, innovation and diffusion, the bulk of their attention has typically concentrated on the latter stages of that process. Such a focus has undoubtedly advanced knowledge of the commercial dimensions of introducing and developing new technologies; it has, however, had little light to shed on the topics of invention, technological creativity and knowledge production. Where do ideas come from? As Weitzman (1996, p. 209) notes, in economics

\footnotetext{
'New ideas' are simply taken to be an exogenously determined function of 'research effort' in the spirit of a humdrum conventional relationship between inputs and outputs. Essentially, this approach represents a theory of knowledge production that tries to do an end run around describing the creative act that produces the new ideas.
}

Recent evolutionary approaches to technological change have altered this situation little (Dosi 1997; Teece 2000). Although firmly grounded in empirical findings, this research programme has yet to provide an explicit theory of knowledge creation. Instead such approaches offer only a description, albeit a relatively sophisticated one, of the outcome of technological creativity. They tells us that new technologies tend to be incremental, local, firm-specific, and follow certain clearly defined paths as determined by the reigning 
technological paradigm and a range of inducement mechanisms. They do not tell us, however, how new technological ideas with such characteristics actually come about.

On the whole, therefore, other than a dispute over whether the process is essentially a demand- or a supply-driven one, economics has not had much to say about invention. What explains this apparent lack of interest? There seems to be two explanations. Firstly, it is generally believed that invention is of no economic importance, the true economic value of an idea coming of age only with the successful completion of the process of innovation. Secondly, it is often contended that invention simply cannot be modelled. McCloskey (1995, pp. 115-6 and 119-20), for example, has argued that 'profitable creativity ... cannot possibly be mechanical. It cannot possibly be because if it were then everyone would buy the machine and use it. The new technique would then become routine and unprofitable, contrary to the premiss.' In other words, 'creativity itself cannot be produced by formula, or else it would already have been.'

How valid are these views? Let's consider each in turn. Is invention really unrelated to innovation and, hence, unimportant? If a short-term, commercial perspective of technological change is adopted, such a statement has plausibility. A firm choosing which technology to adopt, after all, cares little about from whence the original idea for the technology came. But when we look at the process of technological change from a broader, more dynamic perspective, it seems less persuasive. The reality of the matter is that throughout history economies that have been technologically creative have demonstrated 
considerable flair in both the acts of invention and innovation (Mokyr 1990, p. 11). This is hardly surprising; persistently successful innovation requires a constant stream of new ideas so as to prevent diminishing returns to innovative efforts setting in.

And what of McCloskey's impossibility theorem? Clearly, she is right in stating that existing theories of creativity and invention have proved particularly impotent in producing creativeness on demand. Yet all such an exercise demonstrates is the limits of our existing knowledge, not that there are fundamental limits to what we can possibly know about the subject. McCloskey is also wrong to claim that if we did have a perfect understanding of creativity, profitable invention would come to a halt because everyone would have access to such knowledge. It would not. In the unlikely event that everyone did have a full understanding of the mechanics of creativity, there is no likelihood whatsoever that they would all produce the same, or even similar, ideas. In other words, McCloskey's hypothetical creativity 'machine' would not produce the same widgets. Moreover, it is worth bearing in mind that creativity is a process, not an outcome. While a specific technology can lose its profitability, the creative process almost by definition cannot. The theoretical study of creativity and invention is possible because what it aims to model is the process, not the fruit, of idea generation. Widespread use of such a model would result in an efflorescence of diverse creativity, not the multiple discovery of the same idea.

In short, then, invention and technological creativity are valid and important fields of study. This paper attempts to further discussion among economists of these issues by positing a 
framework for the study of technological creativity. This framework can be applied at the firm, industry or national level. In the next two sections, the generation of new ideas is viewed through the visor of cognitive psychology. This knowledge is then combined in section 4 with the demand for new ideas to arrive at the notion of the short-run equilibrium level of inventive output. The implications of this analysis are discussed in the concluding section.

\section{THE PSYCHOLOGY OF CREATIVITY}

How can we model inventiveness? Ideas occur first in the minds of individuals, so one possibility might be to focus attention on matters that influence individual behaviour; that is on psychology. Indeed, a number of fruitful exchanges between economics and psychology have occurred in the past, particularly in relation to the question of technological creativity. Perhaps the best known of these was Usher's (1954) attempt to explain technological ingenuity with Gestalt psychology.

Recent psychological research has emphasized the importance of cognition and information processing to creativity (Mumford and Gustafson 1988). Much of this literature has focused on the relationship between creativity and different cognitive forms. The most common distinction made is between divergent and convergent thought, where creativity is putatively the province of divergent, or lateral, thinking: a fluid and flexible form of thinking that does not take existing conventions, information and frameworks as givens, but is prepared to ask 
the unaskable and see connections between ostensibly disparate activities (Guildford 1967; DeBono 1971; Christie 1995). In practice, however, the distinction between the different modes of thought has been very difficult to identify. Inasmuch as they exist as separate entities, convergent and divergent thought appear to work together, and indeed are equally necessary, to the discovery of creative solutions (Baffon and Harrington 1981).

Moreover, a survey of creativity studies reveals that the most commonly cited cognitive characteristics of creative persons were their use of existing knowledge as base for new ideas, their mastery of their particular domain, and their alertness to novelty and gaps in the existing knowledge base (Tardif and Sternberg 1988). Each of these are characteristics which one would normally associate with convergent thought: hardly the stuff of the quirky genius endowed with a divergent thought process.

Indeed, a cornerstone of much of the 'new cognitive psychology' of recent years is precisely that creativity is founded in ordinary, not extraordinary, thought. In other words, the same cognitive processes used to resolve everyday matters or problems are also employed to make even the most advanced and abstruse of discoveries. What differs between the two types of activities is not the cognition but the circumstances and the extent of background skills and information needed to come to the conclusion. Put in this way, creativity, thus, boils down to the type of information processing familiar to standard decision making. Creativity, then, is simply a form, albeit an intriguing one, of problem solving. Like most models of problem solving, cognitive psychologists see the process rooted in the past, in one's experiences and previous learning (Simon 1988; Sternberg and 
Davidson 1985; Walberg 1988). The precise nature of the relationship between the past and present, however, is a subject of major disagreement. Three alternatives appear to predominate.

The first of these stems from the old saying that there is nothing new under the sun. The only thing 'new' about new ideas is the manner in which they have combined existing knowledge. This is the combinatorial theory. In its extreme version, it offers a history of creativity that is characterized by the constant recycling and recombination of a finite stock of ideas. It is a popular view probably because of the intuitive appeal of linking present ideas to the past. A recent example of this approach has been offered by Weitzman (1996, p. 209).

Take, for example, the idea of 'night baseball'. In 1935 the Cincinnati Reds invented, so to speak, 'night baseball' with the idea of 'massed floodlights'. In turn, the idea of 'massed floodlights' arose by mating the idea of an 'electricity production and distribution network'. Both of these parent ideas were, more or less, invented by Thomas Edison. The idea of an 'electric light' is itself a hybrid, the first practical example of which was made in 1879 , between the idea of 'artificial illumination' and the idea of 'electricity'. The idea of an 'electricity production and distribution network' was conceived by Edison in the 1880's as an explicit combination of the ideas of 'electricity' with the idea of a 'gas distribution system,' where the electricity is essentially substituted for gas. 
The problem with the combinatorial approach is that it is essentially descriptive rather than analytical. While it certainly seems plausible to state that new ideas often are based upon older ideas, such statements shed no light on either how such new cross-fertilising combinations are actually struck or which ideas are to be wedded together to find a solution to a given problem. In short, the cognitive processes involved are sidestepped. Further, the theory tends to understate the extent of genuine novelty involved. The point is illustrated by the ideational family tree for night baseball outlined above. While the developers of electricity distribution networks clearly had much to learn from the previous experience of gas distribution networks, much more creativity was needed than the mere substitution of electricity for gas. The characteristics of electricity radically differ from gas and exploring these differences and how they influence the optimal form of the network required inter alia the collation of new data, the development of new concepts and the consideration of new parameters. Such activity amounted to more than just the combining of new ideas.

Another common approach purporting to link the past to the present emanates from the limitations, or bounded rationality, of human information processing. The human mind, while in effect an information processing system not unlike a computer, is not an entirely efficient one (Newell and Simon 1972). There are limits to its knowledge acquisition and processing capabilities. According to Simon (1982), for example, humans can typically only retain between two and seven items of information in their immediate, conscious memory. Storing items in long-term memory requires time and effort and is only useful to problem solving if it can be accessed on call. Individuals and organisations thus devise strategies to deal with this 
bounded rationality. One such strategy is to abandon any hope of finding the optimal solution and settle for one that is both attainable and satisfactory. Moreover, in order to cut through the great mass of available information, which in its entirety is well beyond our rather limited processing capabilities, we develop selective search techniques, heuristics that provide a tried-and-tested - and hence routine - method of eliciting a germane sample of the knowledge base (Hogarth 1980; Simon 1982).

A good illustration of this approach is found in Nelson and Winter's (1982) evolutionary theory of the firm, in which the firm, unable to profit-maximize because of bounded rationality, is compelled to satisfice; that is, continue in its routine behaviour as long as a specified rate of return is achieved. The problem is that we are, however, told little about this search process, except that it is local, stochastic and, like everything else the firm does, based on routine. A search may yield adequate doses of information needed for the production of a creative solution, but how is that information synthesized and transformed into the final, novel outcome? Linking past information to the present through the implementation of searches may, like the combinatorial approach, be a reasonable description of a characteristic of the creative process; it is, however, not a theory of ideation.

There is a third possibility which is also based both on a continuity with the past and ordinary thought processes. It emphasizes memory phenomena. It too begins with the identification of a problem, for most studies of problem solving have found that solutions 
appear more readily and of a higher quality when explicit solution criteria have been specified in advance (Farr 1990). But it differs from the other approaches in that it offers a cognitive mechanism - the analogical transfer - that can explain the emergence of novelty out of acquired information. An analogical transfer occurs when information and experiences from one known situation is retrieved and utilized in the search for the solution to an entirely different situation. What is crucial to this type of thinking is the perception of one situation as an analogue for another. In recent years, a number of cognitive psychologists have stressed the importance of analogy to creativity (Weisberg 1993; Langley and Jones 1988; Schank 1988). As Sternberg (1988, p. 3) noted, 'insights are especially likely to occur when insightful problem solvers recognize analogies between new problems they are currently facing and problems they have solved before.' Weisberg (1993, pp. 20-1), for example, maintains that Thomas Edison was a practitioner of analogical thinking. He argues that Edison used his earlier invention, the phonograph, as the analogue for his development of the kinetoscope. Edison's own notes seem to substantiate the claim in that they show that he saw an analogy between his use of the cylinder in the phonograph to record sounds and his need to store visual images for the kinetoscope.

An interesting feature of such a cognitive process is that it is not necessary for the two or more situations involved in an analogical transfer to be superficially similar in nature. Indeed, they may be on the face of it totally unrelated. Thus, for example, the nature of the link between the development of the electricity production and distribution network and older gas distribution networks, discussed earlier, is not a matter of simple technological 
combination, but one of analogical transfer instead; that is, the pioneers of electricity production saw the parallels between the two systems and used this similarity as a source of suggestions for solutions to particular problems that they were forced to confront in devising a network from scratch. In principle, then, what does appear to matter is that the creative individual involved perceives an analogy between situations, and this realisation may offer a potential solution to the problem at hand. ${ }^{1}$

Of course, all such possible solutions will be subjected to vigorous scrutiny, a process which will either reject them as being totally impractical or wrong, throw up new difficulties that need to be resolved or, occasionally, confirm the validity and viability of the ideas. More often than not, however, it will highlight the deficiencies of the original idea. Such deficiencies prompt in turn a new round of thinking, which once again, if necessary, will draw upon analogical transfers from the creator's memory. Such a process of further analysis and modification will either bring about the successful implementation of the idea or its eventual abandonment. As Weisberg's (1993) research points out, though, this process is not always a matter of simply refining the original idea. Rather, the combination of revision and analogical transfer can bring about radical leaps in ideas. Such discontinuities can be brought about in two ways: through the critical analysis of one's own ideas and through exposure to external stimuli that prompt one to perceive new, potentially more fruitful, analogies. Such external stimuli can arise out of chance encounters; alternatively, from, say, a firm

\footnotetext{
${ }^{1}$ Despite their apparent similarity, analogical thinking differs from lateral thinking in at least two ways. First, lateral thinking is based on the idea of extraordinary thought; analogical thinking on ordinary thought. Secondly, lateral thinking involves the perception of links between previously unconnected realms; analogical thinking the transfer of aspects of successful solutions to different circumstances.
} 
perspective, they may be produced by the introduction of new employees within the workplace who bring with them a range of new experiences or by contacts made through professional and trade organisations or networks.

This finding has two interesting implications. Firstly, it illustrates that a discontinuous creative outcome can evolve from ordinary thought processes. Radical solutions, then, are not necessarily the product of the unusual mind. Secondly - and perhaps more importantly to the study of technological creativity - it illustrates how discontinuity can emerge out of learning gained through the acquisition of experience. Typically, such learning by doing is thought to generate only local and incremental change in production technology. Analogical transfer provides an explanation of how radical and minor technological changes can in fact occur from the gradual accumulation of knowledge. One need not presume, as Mokyr (1990) does, that the generation of radically novel technological ideas are determined by a different set of factors than minor improvements.

One of the advantages of analogical transfer is that, unlike other cognitive-based theories, it does offer a clear mechanism by which creative solutions can emerge. In other words, it states how individuals can translate past experiences and learning into new ideas. Analogical thinking, moreover, does not require encyclopaedic knowledge of all fields related to the problem at hand, though, an ability to access such knowledge readily from one's long-term memory is hardly disadvantageous. It seems, though, that sustained creativity can be based on a limited number of, albeit fruitful, analogies. It is claimed, for example, that many of 
Thomas Edison's inventions relied upon just a handful of ideas - namely the cylinder, tuning fork and curved ratchet pawl - which he continued to use with great frequency throughout his inventive career. It seems unlikely that Edison was unusual in this regard. His fondness for the cylinder has been attributed to the inventor's early work experience in telegraphic offices, newspapers and machines shops; workplaces in which machines incorporating cylinders were commonplace. This mechanical familiarity with the cylinder and its properties allowed him to see analogies between the experiences he had acquired in telegraphic offices and entirely different situations (Weisberg 1993).

\section{A FRAMEWORK OF ANALOGICAL LEARNING}

One of the advantages of analogical thinking is that some of its basic properties can be expressed mathematically. If we take analogical transfer to mean that new ideas or learning is brought about through identification of two similar experiences, then a notional analogical learning function can be specified. To get to this function six simplifying assumptions about the nature of experience and learning are necessary. It goes without saying, of course, that this function should not be taken as more than a convenient description of the learning process, whose primary purpose is to reveal the theoretical nature of that process more explicitly.

Assumption 1: Volumes of experience can be measured in terms of a standard unit of experience. 
Assumption 2: That all units of experience have an equal potential of being used in analogical transfer.

Assumption 3: That a given unit of experience cannot be analogically paired with itself.

Assumption 4: That all units of experience can be an analogue for any other experience only once.

Assumption 5: The scale of learning can be measured in terms of a standard unit of learning. Assumption 6: That all units of learning represent a potentially creative solution.

Taken together these assumptions yield an analogical learning function of the form

$$
y=-x+x^{2}
$$

where $y$ is the amount learning attained and $x$, an integer, the quantity of experience acquired. This equation, of course, only represents the rawest potential of analogical transfers. In reality, not all experiential pairings will prompt an analogy. For example, in areas of technological bottlenecks or depleted technological opportunities, the ability to learn may be constrained. Similarly, some pairings may permit several analogies. The extent that this occurs depends on the capabilities and circumstances of the individual and technologies in question. To allow for this, we need to replace Assumption 4 with the following:

Assumption 4(b): That all units of experience can potentially be an analogue for any other experience. 
This assumption permits us to introduce a 'creative efficiency' coefficient to reflect an individual or organization's opportunity and ability to recognize and act upon analogical transfers. The revised analogical learning function thus becomes:

$$
y=\alpha\left(x^{2}-x\right)
$$

where $\alpha$ is the efficiency coefficient. If $x \geq 0$ and $\alpha \geq 0$, then

$$
\delta y / \delta x=\alpha(2 x-1) \geq 0 \text { and } \delta^{2} y / \delta x^{2}=2 \alpha
$$

In other words, marginal learning is positive and accelerates at a constant rate. As long as $\alpha$ $>0$, there are no diminishing returns to experience. The volume of learning, then, is a function of creative efficiency and experience. If creativity in the real world is to be comprehended, the determinants of each of these variables needs to be understood as well. A discussion of each of these variables is given in the following sections.

\subsection{Experience}


Valuable experience can be derived from a variety of sources. The total amount of experience that an individual in a workplace brings to creative problem solving, $\left(x_{\text {TOTAL }}\right)$, can be notionally expressed by the function

$$
x_{\text {TOTAL }}=f\left(x_{p}, x_{f}, x_{n}\right)
$$

where $x_{p}$ is personally acquired experience, $x_{f}$ experience held by the firm, and $x_{n}$ experience acquired through networking. The origins of each of these types of experience differs and, hence, needs to be considered independently.

\section{Personal Experience}

In the realm of technological creativity, most personal experience comes from everyday production, which cultivates in the individuals involved a familiarity with and a wealth of knowledge about the practicalities of their work. This first hand knowledge steadily accumulates over time and is a source of not only one's expertise, but also potentially one's creativity. As Walberg (1988, p. 345) reminds us, 'discovery may occur in an instant, but it usually requires decades of preparation in the special field.'

One can see parallels here with the economic concept of learning-by-doing. By learning-bydoing it is meant the process, first described by Arrow (1962), whereby unit costs decrease as a direct result of accumulating experience. Learning-by-doing takes place by performing 
an activity, the feedback from which gives rise to a response or stimulus by which the efficiency of performing the activity is increased. This may occur either by capability accumulation, which improves skills or organisation, or through pure technological accumulation that improves production equipment. In a sense, learning-by-doing is seen as one of the dynamic benefits of the division of labour in which specialisation in the tasks of production, by permitting the continuous, full-time practice of a few simple operations, brings about improvements in the performance of those tasks.

In his model Arrow took cumulative gross investment as an index of experience because he regarded each new machine produced and put to use as capable of changing the environment in which production takes place. Subsequent research (Lieberman 1984) has continued to see a close relationship between cumulative investment and learning. How does this proposed connection between investment and learning relate to the analogical learning functions outlined above? The learning-by-doing literature implies that $x=f(I)$, where $x$ is experience and $I$ the level of cumulative investment. Analogical thinking implies that $y=f(x)$, where $y$ is the amount of learning. Combining these two functions, we get the standard statement of learning-by-doing, namely that learning is a function of cumulative investment. Such a relation gives rise to learning curves of a functional form dictated by the nature of analogical thinking. The slope of the learning curve, however, is variable and is determined by the precise form of the relationship between investment and experience attainment. In practice, this relationship is likely to vary between firms, industries and investment projects. 
In general, though, the greater the amount of experience stimulated by investment, the steeper the learning curve.

The crucial point about learning-by-doing is that a firm can augment its productivity and reduce costs if it can increase its workforce's experience with the production process. Productive activity generates not only output in the physical sense, but also information that is capable of improving production. It follows that an individual's personal experience should similarly be related to the amount of productive activity in which he or she has engaged.

Does it matter in what capacity one's involvement in productive activity takes? Stiglitz (1987, p. 131) claims that '... by assigning workers a variety of tasks, one may enhance the range of their learning capabilities ... they may then be more flexible in learning capabilities, better able to adapt to a wider variety of circumstances.' This, however, would seem to run counter to the accepted view outlined above that it is precisely that specialisation in, and resulting familiarity with, an activity that imparts the understanding necessary to transform it. This is not to say that Stiglitz's point is wrong. The benefits of broadening workers' experience is commonsensical enough, though there would appear to be a trade-off between broader and more specialized experience. Finding the optimal mixture of the two types of experience even at the best of times must be extremely difficult. Moreover, to assume the existence and search for this optimal balance of experience presupposes on the part of the firm an awareness of learning that simply may not exist. One further aspect that may affect an individual's ability to acquire experience is their employment history. Here the length of 
time that the employee spends performing related operations both within a firm and the industry as a whole as well as his or her range of work experience outside the industry seem germane. A diversity of experience should, ceteris paribus, offer an individual the potential (as some of it may be totally irrelevant to his or her current employment) of perceiving a wider variety of analogies and, hence, facilitate analogical transfer. However, if workers never stay in one place long enough to learn, then the experiences may be totally lost. Spells of un- and underemployment, casual and part-time employment, and frequent re-allocation of labour to different tasks within the workplace to meet short-term exigencies may undermine the acquisition of valuable experience.

\section{Firm experience}

As most technological creativity occurs within the work environment, one can in principle draw upon the accumulated experience and knowledge of the workplace. Over time, firms, for example, become involved in a wide variety of activities and experiments, and this opens up a world of experience that is unknown to the individual. Indeed, much of the knowledgebased view of the firm found in recent literature regards such storehouses of knowledge as the ultimate source of the firm's sustained competitive advantage (Spender and Grant 1996). In practice, though, its effectiveness depends on the firm's ability to retrieve and diffuse the appropriate information, so that it is made available to the right person at the right time. One factor that influences this ability is the tacitness of the firm's knowledge. In other words, is the knowledge the firm holds of a form that would enable it to be readily transferable 
between departments and individuals in the firm, or is it instead of such a subjective, internalized nature that it can only be acquired through personal experience or personal interaction with experts? To Nonaka et al. (2000), this relationship between explicit and tacit knowledge is integral to the knowledge-creating process. The ability of the firm to make use of this knowledge depends on a number of factors, including the ability and willingness of the firm to codify its internal knowledge (Cowan and Foray 1997), the nature of in-house mechanisms and rules to keep organisational secrets (Liebeskind 1997), the rate of labour turnover (Magee 1997), and the structure of information flows within the firm (Aoki 1988). These factors are considered in more detail later.

\section{Network experience}

Another way firms and individuals can expand the extent of their learning is to share their experiences with other firms or individuals in similar or related situations. It is well-known, for example, how capital producers and manufacturers in various industries can, and indeed do, often co-operated with each other to achieve beneficial results all round. Intra-industry co-operation also provided ample scope for similarly mutual gains to be had. According to Allen (1983), many American iron and steel producers of the nineteenth century willingly shared their innovations with competitors in the belief that through such frank interchange of ideas and problems, the well-being of all concerned would be augmented. Such inter-firm contact is facilitated by trade associations, conventions, and journals. These organisations and publications play an important role in creating a forum for the discussion of shared 
problems and their resolution. As such, they represent a potentially valuable source of learning and expertise. As Von Hippel (1988) points out such exchanges of know-how may also be conducted less publicly through direct contact between individuals operating in rival companies, an informal trade that continues as long as its participants believe that its reduces innovation-related costs by more than it undermines the firm's competitive advantage.

Sharing of information relevant to innovation also occurs through organisational arrangements such as networks. These networks connect groups of firms with a commonality of interest together in the aim that through a degree of collaborative activity, mutual benefits may be had by all participants. Networks can take a variety of forms but most commonly occur between users and producers of a certain product and between firms operating in the same industry or region. Networks are seen to enhance learning in a number of ways, the most important of which are:

- by exposing individuals and firms to a much broader range of experience (DeBresson and Amesse 1991; Galambos with Sewell 1995)

- $\quad$ by spreading the cost of $R \& D$ and other inventive activity across a large number of organisations (DeBresson and Amesse 1991);

- by reducing the costs of information and experience to members of the network (Imai 1989);

- by setting industry standards and norms which facilitates the codification and diffusion of knowledge (DeBresson and Amesse 1991); 
- $\quad$ by reducing the unnecessary duplication of research effort (Gambardella 1995); and

- by encouraging specialisation of research effort (Gambardella 1995).

Like firm experience, the pool of experience offered by operating within a network represents only a potential. A number of factors influence the extent to which that pool grows. Such factors include:

- the suitability and desirability of forming networks. Networks are more appealing at time of economic and technological turbulence, when uncertainty encourages cooperation (Rosenkopf and Tushman 1998). By contrast, political and social instability appears to activate against the formation of stable networks (Bianchi and Bellini 1991).

- The size of network. A network with too few participants tends to limit the potential for fruitful interaction (Teubal et al. 1991).

- The social, cultural and geographical cohesiveness of the network. Networks are much more resilient and productive when comprised of members of similar backgrounds, origins and values living and working in close proximity to each other (Bianchi and Bellini 1991; Scott 1991).

- The degree of trust within the network. Networks in which opportunistic behaviour persists breeds distrust and, hence, discourages the sharing of experiences (Casson and Cox 1993). 
- The strategic cohesiveness of the network. Are the members of the network really seeking similar goals? If the objectives differ, the incentive and value of network interaction is diminished. Firms, thus, have less incentive to share (Lawton Smith et al. 1991).

- The compatibility of assets and knowledge within the network. If production technologies differ significantly between participants, the amount of experience that can be transferred between members may be very limited. Awareness of these perceived incompatibilities may encourage further disuse of network exchange (DeBresson and Amesse 1991).

\subsection{Creative efficiency}

Creative efficiency concerns the ability of individuals, groups and organisations to turn experiences into learning and new ideas. Such efficiency is clearly governed by a large number of considerations, but notionally we can express it as the function

$$
\alpha=f\left(\alpha_{c}, \alpha_{k}, \alpha_{m}, \alpha_{o}\right)
$$

where $\alpha_{c}$ represents cognitive efficiency or the ability to think analogically, $\alpha_{k}$ knowledge efficiency, $\alpha_{m}$ motivational efficiency, and $\alpha_{o}$ organisational efficiency. ${ }^{2}$

\footnotetext{
2 If it is assumed that all relevant creative effort is tightly focussed on a specific technology, then, clearly creative efficiency is also influenced by the opportunities for further development that that technology offers. Thus, an exhausted technology can be expected to offer little scope for learning. This paper, however, assumes that the locus of creativity is not so narrowly defined. In fact, the logic of
} 


\section{$\underline{\text { Cognitive efficiency }}$}

The ability to think analogically and, thus, have the capability of perceiving similarities between different situations is a basic characteristic of the human mind. We are all capable of it, though, not all of us manage to do it with the same degree of proficiency (Farr and Ford 1990). While some aspect of individual cognitive ability is genetically determined, most psychologists, however, believe that for many individuals there is significant room for improvement. Practical experience with problem solving and interaction with successful innovators can build up competency in the appropriate forms of cognition (Simon 1986). Stiglitz (1987) has called this capability learning-to-learn and sees it as a logical extension of the concept of learning-by-doing. In other words, it appears that the more that one learns, the easier subsequent learning becomes; a phenomenon whose roots lie in the development of cognitive skills attained through experience. Exposure to mentors at an early stage of one's career can also teach one successful problem-solving techniques (Weisberg 1993; Farr and Ford 1990). A broadening of the range of work experience likewise may facilitate the perception of similarities between different circumstances. Movement between departments, between firms and involvement in network activity can thus all add to a database of experience, which can promote analogical thought.

analogical thinking implies that there is no reason to suppose ex ante that, as a general rule, an analogy derived from experience with one technology cannot be applied to another entirely different technology. 
Cognitive practices can also to an extent be taught. Education can improve not only an individual's ability to perform a task, but also to understand and draw connections between different phenomena. The form of the instruction, however, is important. Above all else, it appears analogical thinking is best enhanced by instruction from a in-depth, problemorientated perspective. By contrast, instruction by means of purely abstract analysis and superficial case studies is less likely to engender creative thought (Weisberg 1993).

This type of detailed problem-based instruction can in principle be applied to any form or level of education. It suggests that the training of even research scientists must go beyond the mastery of theory and techniques to include the analysis and demonstration of problem solving in the R\&D laboratory. This might be carried out through a combination of the intricate study of case histories and placement in the field, where the student would not only exercise their knowledge and laboratory skills, but also observe - and to an extent engage in - the on-going process of problem solving first hand. The scope for problem-focused instruction is even greater with vocational training. Teaching techniques that enhance analogical transfer is, thus, one way to bring the reality of technical training more in line with its ideal and ensure that graduates are more likely to identify and resolve problems that occur in their day-to-day work.

\section{$\underline{\text { Knowledge efficiency }}$}


In essence, the concept of knowledge efficiency refers to the suitability of various forms of human capital endowment for analogical thinking. It can be distinguished from cognitive efficiency in that it is not concerned with acquiring the appropriate thought processes, but rather the optimal knowledge base. What type of knowledge best facilitates analogical transfer? Firstly, it needs to be pointed out that this is not a question of subject-matter. The substance of the requisite knowledge base is contingent on the nature of the problem area concerned. A research scientists working on DNA, therefore, is obviously going to need a more much extensive knowledge of advanced genetics than an engineer designing a new type of seatbelt for a car. That said, is there anything that is characteristic about analogygenerating knowledge, irrespective of context? Psychological research on problem solving provides little evidence of spontaneous transfer based on remote analogies; that is, instantaneous solutions are rarely found by analogy between entirely unrelated situations. Novelty tends not to come out of the blue. In part this seems to be because it is the recognition of surface elements that to a large extent determines which information is retrieved from memory in order to form the basis of an analogy (Weisberg 1993). This, in turn, would suggest that deep, domain-specific expertise is highly conducive to creative problem solving. This is hardly surprising. Our understanding of DNA is not likely to be advanced very far by a tax accountant, just as a geneticist is not the first person one would naturally turn to find ways to reduce one's tax burden. But the attainment of the core knowledge of one's field is essential not only for competence, but also for creativity. To determine that something is both novel and useful requires knowledge of what has gone before and what is the current state of play - in other words, detailed knowledge of one's 
field. Without such knowledge the reinvention of the wheel is always a possibility. All of this, of course, begs the question of what is expertise. Expertise requires more than having the appropriate qualifications, it means having a practical mastery of your field. Much of this mastery may be tacit: it is experiential and internal in nature rather than analytical and communicable. Such a view of expertise, if correct, strengthens the value of problemorientated instruction. All in all, then, an important implication of analogical thinking is that it provides support for the contention that human capital accumulation is essential to the attainment of benefits via learning. Investment in domain-specific skills and knowledge enhances creativity (Walberg 1988; Weisberg 1993).

\section{$\underline{\text { Motivational efficiency }}$}

The act of creation is a conscious one. It is also requires commitment, as, for example, the acquisition of expertise in any field takes considerable time and effort. It stands to reason, then, that to some degree the extent of creativity that takes place can be strongly influenced by motivational factors. Unsurprisingly, motivation lies at the heart of many psychological theories of creativity. An array of factors can affect motivation (Amiable 1983). McClelland (1962), for example, has written of the achievement motivation, an internal drive for success unique to achieving and creative individuals, which is said to appear in childhood. The economics literature on technological creativity, however, has tended to place greater emphasis on two other variety of factors: values and economic gain. 
The value system of an individual matters to creativity for it sets boundaries within which creative minds can work without fear of sanction. Ideas can be dangerous and fly in the face of traditional societal conventions and beliefs, and awareness of this potential may well demotivate many individuals sufficiently to hinder creativity. Similarly, a society's hierarchy of values may be such as to ascribe little merit and status to technological creativity. In such a setting, one would find few willing to devote their attentions to such a pastime (Mokyr 1990; Stiglitz 1987).

Individuals may also be motivated to invent by the expected payoff from their ideas (Farr and Ford 1990). The greater the perceived economic benefit, the greater effort and resources put into inventive activity. As much of this activity tends to take place in the workplace, industrial relations and the institutional setting, in which the employee finds himself, can in this respect be germane. Working in a climate of industrial conflict characterized by confrontation between labour and capital and enmity for the owner, a worker may have no desire to help the boss out by improving his machinery; at least not unless something is given in return.

This raises a pertinent question. It is a well-established aspect of virtually all theories of technological development that the appropriability of the returns to innovative activity is an important determinant of the level and rate of innovation that actually occurs (Levin et al. 1985). This presumes that there is a clear proprietor of the innovation: viz., someone or some firm that can claim to have fundamentally invented and developed the invention and 
can assert this property right. In the case of innovation via learning attained on the shop-floor it is not exactly clear who this 'owner' should be. In most instances it is the worker that actually sees the problem and finds its solution. The worker thus would seem to be the owner, yet the employer may claim that the development would not have not been possible without the facilities and stimuli provided by the firm. Moreover, such activities, the employer would argue, are part of the worker's job for which he or she is already being remunerated. The problem then revolves around job control and description. In this light, it is clear that arrangements that alienate workers and discourage learning are not in any firm's best interest. In fact, if the benefits of experience are important enough to the firm's wellbeing, it would seem prudent for employers to opt for remuneration plans that were specifically tailored to maximize the generation of home-grown inventiveness. Apart from productivity-tied wage rates, other incentive-driven remuneration policies that have shown some success in these regards include profit-sharing plans, bonuses, and promotions for those who introduce or suggest useful ideas (Blanchflower and Oswald 1987; Estrin et al.1987; Magee 1997). Such schemes may act to enhance motivational efficiency.

\section{$\underline{\text { Organizational efficiency }}$}

A large proportion of technological creativity occurs within organisations. The concept of organisational efficiency attempts to capture how features of such organisations can impact on the scale of inventive activity. Managerial structure and the organisation of research and innovation within the firm and industry, for example, clearly matter. For all but the simplest of adjustments, improvements in production processes, especially where interrelatedness is a factor, will require changes to be made that disrupt production, possibly even bringing it 
temporarily to a standstill. Any action upon a worker's idea would need the approval of management. The internal structure and organisation of the firm, however, may make this difficult to obtain. Channels through which information between the shop-floor and management can flow are essential.

There are a number of features of firm structure that may affect the flow of information and experience. These include:

- rigid hierarchies, which erect barriers, or 'elevator mentality', between different branches of the firm and inhibits communication (Aoki 1988; Kanter 1983);

- an over-centralisation of decision-making, which can leave a creative individual without the freedom and/or information necessary to act (Lovelace 1986; Zaltman et al. 1973);

- highly formalized rules of interaction within the firm, which prevent individuals from seeking and sharing new sources of information both outside and inside the firm (Rogers 1983; Aoki 1988; Liebeskind 1997);

- an overspecialisation of functions, which inhibits intrafirm collaboration and exchange of information (Aoki 1988); and

- fellow employees in positions of power who, perhaps out of jealousy or an overactive sense of self-preservation, deliberately discourage those under their charge from informing management on how things could be run better (Magee 1997). 
The form in which information is communicated is also important. It is believed that the human mind tends to store and understand information as experiences within particular contexts, rather than as isolated facts (Weisberg 1993). These memories may well be visual by nature. As a result, information is best conveyed vividly; that is in a manner that provokes images, interest and meaning (Nisbett and Ross 1980; Farr 1990).

Employment practices matter as well. A high rate of labour turnover in a firm, for example, may discourage creativity for two reasons. Firstly, it may mean that valuable firm experience and information is being steadily lost as employees leave the workforce, taking with them their acquired knowledge. Secondly, it may also mean that much of the experience and information that the firm actually does retain becomes less accessible, because the only people who may know about its existence are no longer with the company. In effect, the firm can become ignorant of parts of its own knowledge base. ${ }^{3}$ Job demarcation is another consideration. It goes without saying that to change a process one must first have a sound understanding of it. The task of the worker, then, must be one that enables him or her to gain such an understanding. But when the task in question is performed as a taught routine, or where the job is so isolated from the rest of the process that one cannot put the task into proper perspective, the opportunities for acquiring such an understanding may not be great. This is one of the disadvantages of a too fine a degree of specialisation. Job rotation, or multitasking, can circumvent this problem. But by moving workers between tasks on a

\footnotetext{
${ }^{3}$ Note that if resistance to new ides increases with age, then the loss of long-serving personnel may not be so deleterious to organizational efficiency.
} 
regular basis, firms not only facilitate an understanding of the production process, they also encourage the exchange of information and the acquisition of a diverse, domain-specific expertise by their workforce. Such factors are clearly relevant to technological creativity.

Finally, the ability to exploit network experience is also influenced by organisational considerations. These considerations include the:

- absence of centralized co-ordination within the network, a result of which is the inability to convey information effectively Teubal et al. 1991);

- lack of flexibility in the functioning of the network, which prevents its ability to respond to new challenges and ideas (Glasmeier 1991);

- power struggles and rivalries within the network, which restrict its effectiveness (DeBresson and Amesse 1991);

- the 'Not-Invented-Here' syndrome, which causes firms to discount the value of information and ideas coming from other firms (Lawton Smith et al. 1991); and

- the failure of participating firms to invest in their own internal capabilities and thus effectively utilize network experience (Cohen and Levinthal 1990; Tripsas 1997).

\section{DEMAND AND THE SHORT-RUN EQUILIBRIUM LEVEL OF INVENTIVE OUTPUT}


One implication of the analogical learning function outlined above is that one would expect it over time to give rise to an accelerating rate of invention. Reality, however, suggests that this is not the case. At any point of time, inventiveness is actually constrained by the level of demand for domestic inventive output evinced by the society, firm or industry under consideration. It is often erroneously claimed that the demand for new ideas is insatiable, and, hence, demand can be regarded as a passive force in the creation of novelty. Such an assertion, however, confuses demand with human aspirations. We all may like to live in a palace, yet this does not mean that the demand for palaces is consequently unlimited. Like all demands, the demand for locally generated inventive output is constrained by our economic and sociological circumstances. ${ }^{4}$ Notionally, this demand at any point of time can be depicted by the function

$$
D I=f\left(P_{l}, P_{T}, R, E, V\right) .
$$

Here, $P_{I}$ represents the cost incurred in acquiring and bringing together the factors, personnel and intellectual property needed to invent and make ideas commercially viable. These costs are determined in the market for such inputs, which exhibit downward-sloping demand and upward-sloping supply curves, implying that a greater supply of inputs can be had only by raising their prices. One would expect $D I$ and $P_{I}$ to be negatively related. $P_{T}$ represents the costs of acquiring comparable new ideas from outside through technology transfers. In a world of deepening and widening economic and technological integration, this should become an increasingly important factor (Magee 1999). $R$ is the financial resources made available for inventive activity and the development of its fruits. $E$ is the expected rate

\footnotetext{
${ }^{4}$ In itself, the demand for new ideas is also a major topic that calls for much more study by and attention from economists.
} 
of return of developing new ideas in the current and foreseeable economic and institutional setting. One would expect a positive relationship between these and the degree of invention experienced (Schmookler 1966). Finally, $V$ represents the values held by the society, company or individual about technology. The prevalence of attitudes that oppose the development of new technologies and channel creative efforts into other pursuits, for example, may dampen the demand for domestic inventiveness.

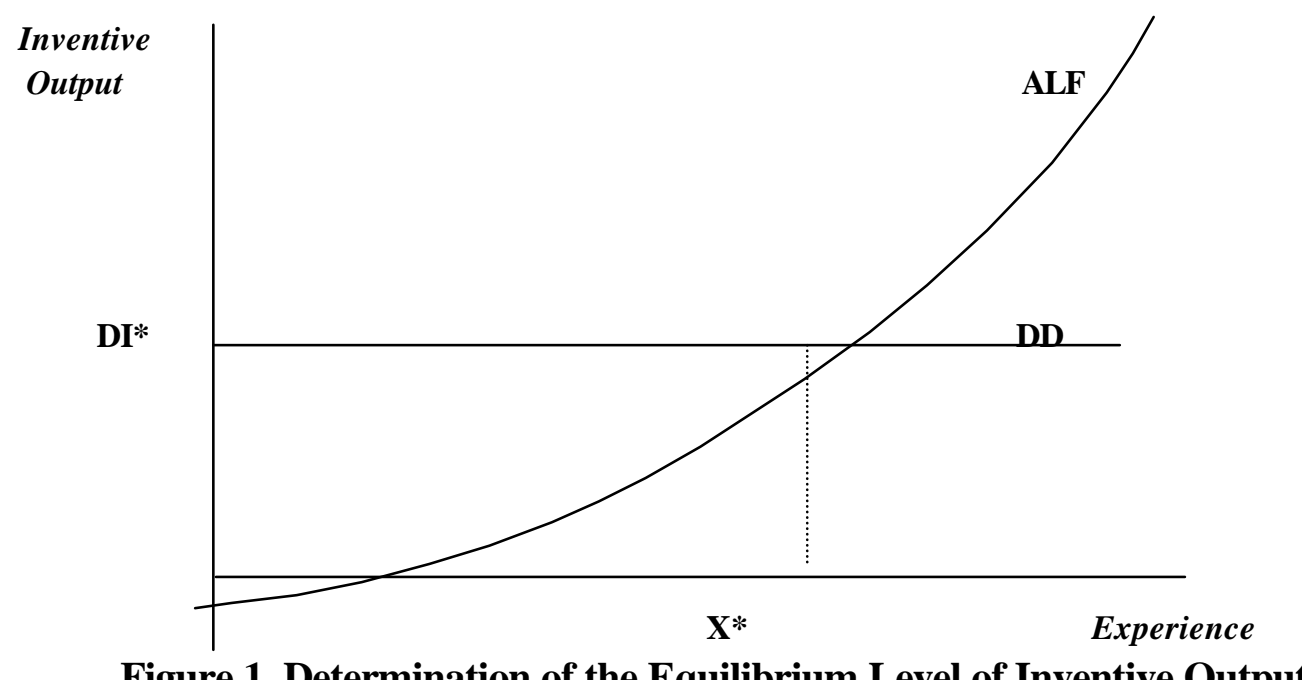

Figure 1. Determination of the Equilibrium Level of Inventive Output

Given the values of each of these variables, the current level of demand for locally generated inventive output $\left(D I^{*}\right)$ can be captured by the horizontal line labelled $D D$ in Figure 1. In this diagram, the curve $A L F$ represents the analogical learning function. Given the existing degree of creative efficiency, it is clear that the demand for inventive output can only be met where $D D$ intersects $A L F$ at $X^{*}$. This is the equilibrium level of domestically produced inventive output. At this point, the demand for new ideas exactly matches its supply. Although this equilibrium is in effect an abstract concept that may be hard to pinpoint in reality, one would nonetheless expect there to be a tendency for economies, industries and 
firms to converge on this point. If $X^{*}>X^{a}$, where $X^{a}$ is the actual level of experience, then there is clearly going to be unmet demand for local invention. This excess demand can be resolved in two ways: firstly, by reorganising the workplace so as to increase overall experience levels, and secondly, by enhancing creative efficiency. When there is a significant shortfall of invention, the latter option is likely to be the more important remedy. Improving creative efficiency, however, usually requires the utilisation of more inventive inputs, which, in turn, raises $P_{I}$ and lowers $D I^{*}$. In other words, in Figure 1, $A L F$ rotates to the left and $D D$ will shift down, till a point is reached where equilibrium is restored. Conversely, when there is an excess supply of invention (where $X^{*}<X^{a}$ ), a backlog of unused inventive ideas will develop. In such a circumstance, equilibrium is restored, when deemed necessary, by reducing experience levels and redundant creative efficiency (either through disinvestment in inventive infrastructure or by an exodus of inventive inputs), actions that will lower both the rate of invention and $P_{I}$ until all unrequired inventive output is eliminated.

One aspect of this framework worth emphasising is the importance it ascribes to both demand- and supply-side considerations in the process of invention. This can be contrasted with the more usual focus of the literature on the dominance of one side of the market over the other. Such a focus would appear misplaced. The fact of the matter is that expanding creative efficiency without a concomitant rise in demand will prove just as unsuccessful in stimulating invention as increasing demand when the inventive capability is lacking. High and sustained levels of technological creativity, therefore, require both the expansion of demand and creative efficiency. A further implication of this analysis is that perceptions of 'poor' 
inventive performance can come about for four reasons. Firstly, a limited degree of demand or creative efficiency - or indeed both - that results in an inventive equilibrium considered by many local observers to be too low. Secondly, when there is insufficient scope to improve creative efficiency to a point where all excess demand for inventive output can be eradicated. Thirdly, when, perhaps because of incomplete information, uncertainty or ideological beliefs, the consumers of local inventive output have an inadequate subjective model of the inventive process. This might take place, for example, when the state perseveres in demanding a level of domestic inventive output that is well beyond any realistic assessment of local capabilities, creating as a consequence a persistent excess demand and frustration at the lack of progress. Finally, from society's perspective, creative underachievement will also arise when the private demand for invention fails to incorporate the true social benefits of those ideas.

\section{CONCLUSION}

Invention is a terra incognita of economics. While the economies of learning have become standard features of the economic analysis of technological change, they have been presented more often than not as stylized facts, rather than processes whose underpinnings and determinants deserve fuller investigation. This paper has attempted to begin to fill this hiatus in our knowledge by exploring a form of cognition, analogical transfer, which is thought by many researchers to lie at the heart of successful creativity. It has shown how such analogical thought can give rise to a theoretical framework, in which disparate factors pertaining to creativity can be pieced together to yield an explanation of the level of inventive 
output experienced. Of course, no claim of definitiveness is, or can be, made here. The framework that has been proposed in this paper merely represents the first, tentative step towards a fuller understanding of the economics of invention. It is hoped that this paper will encourage more economists to undertake that work and to think further about the origins of new technologies.

\section{References}

Allen, R. C. (1983) Collective Invention. Journal of Economic Behavior and Organization 4(1), 1-24.

Amiable, T. M. (1983) The Social Psychology of Creativity. New York: SpringlerVerlag.

Aoki, M. (1988) Information, Incentives and Bargaining in the Japanese Economy. Cambridge: Cambridge University Press.

Arrow, K. (1962) The Economic Implications of Learning by Doing. Review of Economic Studies 29(1), 155-173.

Baffon, F. and Harrington, D. M. (1981), Creativity, Intelligence, and Personality. Annual Review of Psychology 32, 439-476. 
Bianchi, P. and Bellini, N. (1991) Public Policies for Local Networks of Innovators. Research Policy 20(3), 487-497.

Blanchflower, D. G. and Oswald, A. J. (1987) Profit Sharing - Can it Work? Oxford Economic Papers 39(1), 1-19.

Casson M. and Cox, H. (1993) International Business Networks: Theory and History. Business and Economic History 22(1), 42-53.

Christie, D. (1995) Towards an Understanding of Intelligence, Creativity and Achievement. In P. Gouk (ed.), Wellsprings of Achievement: Cultural and Economic Dynamics in Early Modern England and Japan. Aldershot: Variorum, 26-46.

Cohen, W. M. and Levinthal, D. A. (1990) Absorptive Capacity: A New Perspective on Learning and Innovation. Administrative Science Quarterly 35(March), 128-152.

Cowan, R. and Foray, D. (1997) The Economics of Codification and the Diffusion of Knowledge. Industrial and Corporate Change 6(3), 595-621.

DeBono, E. (1971) Lateral Thinking for Management. New York: McGraw-Hill.

DeBresson, C. and Amesse, F. (1991) Network of Innovators: A Review and Introduction to the Issue. Research Policy 20(3), 363-379.

Dosi, G. (1997) Opportunities, Incentives and the Collective Patterns of Technological Change. Economic Journal 107(September), 1530-1547.

Estrin, S., Grout, P. and Wadhwani, S. (1987) Profit-sharing and Employee Share Ownership: An Assessment. Economic Policy 4 (April), 13-52. 
Farr J. L. and Ford, C. M. (1990) Individual Innovation. In M. A. West and J. L. Farr (eds.), Innovation and Creativity at Work: Psychological and Organizational Strategies. Chicester: John Wiley \& Sons, 1990, 63-80.

Farr, J. L. (1990) Facilitating Individual Role Innovation. In M. A. West and J. L. Farr (eds.), Innovation and Creativity at Work: Psychological and Organizational Strategies. Chicester: John Wiley \& Sons, 207-230.

Galambos L. with Sewell, J. E. (1995) Networks of Innovation: Vaccine Development at Merck, Sharp \& Dohme, and Mulford, 1895-1995. New York: Cambridge University Press.

Gambardella, A. (1995) Science and Innovation: The US Pharmaceutical Industry during the 1980s. Cambridge: Cambridge University Press.

Glasmeier, A. (1991) Technological Discontinuities and Flexible Production Networks: The Case of Switzerland and the World Watch Industry. Research Policy 20(3), 469-485.

Guildford, J. P. (1967) The Nature of Human Intelligence. New York: McGraw-Hill.

Hogarth, R. M. (1980) Judgement and Choice: The Psychology of Decision. New York: Wiley.

Imai, K. (1989) Evolution of Japan's Corporate and Industrial Networks. In B. Carlsson (ed.), Industrial Dynamics: Technological, Organizational, and Structural Changes in Industries and Firms. London: Kluwer, 123-152.

Kanter, R. M. (1983) The Change Masters. New York: Simon Schuster. 
Langley P. and Jones, R. (1988) A Computational Model of Scientific Insight. In R. J. Sternberg (ed.), The Nature of Creativity: Contemporary Psychological Perspectives. Cambridge: Cambridge University Press, 171-201.

Lawton Smith, H., Dickson, K. and Smith, S. L. (1991) 'There are Two Sides to Every Story': Innovation and Collaboration within Networks of Large and Small Firms. Research Policy 20(3), 457-468.

Levin, R.C., Cohen W. M. and Mowery, D. C. (1985) R\&D, Appropriability, Opportunity and Market Structure: New Evidence on Some Schumpeterian Hypotheses. American Economic Review 75(2), 20-24.

Lieberman, D. (1984) The Learning Curve and Pricing in the Chemical Processing Industries. Rand Journal of Economics 15(2), 213-228.

Liebeskind, J. P. (1997) Keeping Organizational Secrets: Protective Institutional Mechanisms and their Costs. Industrial and Corporate Change 6(3), 623-63.

Lovelace, R. F. (1986) Stimulating Creativity through Managerial Intervention. $R \& D$ Management 16, 161-174.

Magee, G. B. (1997) Productivity and Performance in the Paper Industry: Labour, Capital and Technology in Britain and America, 1860-1914. Cambridge: Cambridge University Press.

Magee, G. B. (1999) Technological Development and Foreign Patenting: Evidence from Nineteenth-Century Australia. Explorations in Economic History 36, 344-359.

McClelland, D. C. (1962) The Achieving Society. Princeton: Princeton University Press. 
McCloskey, D. N. (1995), 1066 and a Wave of Gadgets: The Achievements of British Growth. In P. Gouk (ed.), Wellsprings of Achievement: Cultural and Economic Dynamics in Early Modern England and Japan. Aldershot: Variorum, 114-132.

Mokyr, J. (1990) The Lever of Riches: Technological Creativity and Economic Progress. Oxford: Oxford University Press.

Mumford, M. D. and Gustafson, S. (1988) Creativity Syndrome: Integration, Application, and Innovation. Psychological Bulletin 103(1), 27-43.

Nelson, R. R. and Winter, S. (1982) An Evolutionary Theory of Economic Change. Cambridge, Mass.: Belknap.

Newell, A. and Simon, H. A. (1972) Human Problem Solving. Englewood Cliffs, N.J.: Prentice-Hall.

Nisbett, R. and Ross, L. (1980) Human Inference: Strategies and Shortcomings of Social Judgement. Englewood Cliffs, N.J.: Prentice-Hall.

Nonaka, I., Toyama R. and Nagata, A. (2000) A Firm as a Knowledge-creating Entity: A New Perspective on the Theory of the Firm. Industrial and Corporate Change 9(1), 120.

Rogers, E. M. (1983) Diffusion of Innovations. New York: Free Press, 1983.

Rosenkopf L. and Tushman, M. L. (1998) The Coevolution of Community Networks and Technology: Lessons from the Flight Simulation Industry. Industrial and Corporate Change 7(2), 311-346. 
Schank, R. C. (1988) Creativity as a Mechanical Process. In R. J. Sternberg (ed.), The

Nature of Creativity: Contemporary Psychological Perspectives. Cambridge:

Cambridge University Press, 220-241.

Schmookler, J. (1966) Invention and Economic Growth. Cambridge, MA: Harvard University Press.

Scott, A. J. (1991) The Aerospace-electronics Industrial Complex of Southern California: The Formative Years, 1940-1960. Research Policy 20(3), 439-456.

Simon, H. A. (1982) Models of Bounded Rationality. Cambridge, Mass.: Harvard University Press, 1982.

Simon, H. A. (1986) How Managers Express their Creativity. Across the Board (March), $11-16$.

Simon, H. A. (1988) Understanding Creativity and Creative Management. In R. L. Kuhn (ed.), Handbook for Creative and Innovative Managers. New York: McGraw-Hill, 1124.

Spender J. C. and Grant, R. M. (1996) Knowledge and the Firm: Overview. Strategic Management Journal 17(Winter), 5-9.

Sternberg R. J. and Davidson, J. E. (1985) Cognitive Development in the Gifted and Talented. In F. D. Horowitz and M. O'Brien (eds.), The Gifted and Talented. Washington D.C.: American Psychological Association, 103-135.

Sternberg, R. J. (1988) Introduction. In R. J. Sternberg (ed.), The Nature of Creativity: Contemporary Psychological Perspectives. Cambridge: Cambridge University Press, 110. 
Stiglitz, J. E. (1987) Learning to Learn, Localized Learning and Technological Progress. In

P. Dasgupta and P. Stoneman (eds.), Economic Policy and Technological Performance. Cambridge: CUP, 1987), 125-153.

Tardif, T. Z. and Sternberg, R. J. (1988) What Do We Know about Creativity? In R. J. Sternberg (ed.), The Nature of Creativity: Contemporary Psychological Perspectives. Cambridge: Cambridge University Press, 429-440.

Teece, D. J. (2000) Firm Capabilities and Economic Development: Implications for the Newly Industrializing Economies. In L. Kim and R. R. Nelson (eds.), Technology, Learning and Innovation: Experiences of Newly Industrializing Economies. Cambridge: Cambridge University Press, 105-128.

Teubal, M., Yinnon, T. and Zuscovitch, E. (1991) Networks and Market Creation. Research Policy 20(3), 381-392.

Tripsas, M. (1997) Surviving Radical Technological Change through Dynamic Capability: Evidence from the Typesetter Industry. Industrial and Corporate Change 6(2), 341-377. Usher, A. P. (1954) A History of Mechanical Inventions. Cambridge, Mass.: Harvard University Press.

Von Hippel, E. (1988) The Sources of Innovation. Oxford: Oxford University Press.

Walberg, H. J. (1988) Creativity and Talent as Learning. In R. J. Sternberg (ed.), The Nature of Creativity: Contemporary Psychological Perspectives. Cambridge: Cambridge University Press, 340-361.

Weisberg, R. W. (1993) Creativity: Beyond the Myth of Genius. New York: W. H. Freeman and Company. 
Weitzman, M. L. (1996) Hybridizing Growth Theory. American Economic Review 85(2), 207-212.

Zaltman, G., Duncan, R. and Holbek, J. (1973) Innovations and Organizations. New York: Wiley. 